\title{
Factors associated with initiation and persistence of urate-lowering therapy
}

Mats Dehlin ${ }^{1 *}$ (D) Emin Hoxha Ekström², Max Petzold ${ }^{3,4}$, Ulf Strömberg ${ }^{4}$, Gunilla Telg ${ }^{5}$ and Lennart T. H. Jacobsson ${ }^{1}$

\begin{abstract}
Background: Gout is the most common inflammatory arthritic disease and is caused by crystal deposition secondary to persistent hyperuricemia. Etiological treatment with urate-lowering therapy (ULT) has been available since the 1950s but previous studies have demonstrated suboptimal degree of treatment. In recent years we have seen recommendations for ULT earlier in the course of the disease, but there are few contemporary reports reflecting the current situation. Therefore we set out to investigate proportion receiving and persisting with ULT after gout diagnosis and predictors thereof.

Method: A population-based cohort study using regional and national population-based registers. Cohort of patients $(n=7709)$ from western Sweden with incident gout aged 18 years and above from 2011 to 2013. An incident case of gout was defined as having been given a diagnosis of gout (ICD-10 M10, M14.0-14.1) not preceded by a gout diagnosis or a dispensation of ULT during the previous 5 years. Main outcome measures were cumulative incidence and predictors for start of, and persistence with, ULT in gout.

Results: Within the first year after first gout diagnosis, 32\% received ULT. Male sex, presence of diabetes or cardiovascular comorbidity, reduced kidney function but not diagnosed "end-stage kidney failure" increased the likelihood of receiving ULT. Of those starting ULT a majority (75\%) did not persist with ULT treatment within the first 2 years. Age $<50$ years, lack of comorbidities, and "normal kidney function" or "end-stage kidney failure" were associated with non-persistence with ULT.

Conclusions: Only a minority of patients received ULT and a majority of these did not persist with treatment over the next 2 years. However, the older patients with renal impairment and comorbidities, possibly suffering from a more severe gout disease, were more likely to receive and persist with treatment. There is thus still room for considerable improvement with regards to management of ULT in gout.
\end{abstract}

Keywords: Gout, ULT, Persistence

\section{Background}

Gout is the most common inflammatory arthritic disease and is caused by crystal deposition secondary to persistent hyperuricemia. It is also one of the few curable forms of arthritis. Gout is associated with higher age, male sex and several comorbidities, including renal dysfunction, metabolic syndrome, cardiovascular disease (CVD) and diuretic medication [1]. Gout has also in numerous studies been shown to predict mortality and CVD events [1], outcomes which have been suggested to be decreased with uratelowering therapy (ULT) [2, 3]. Etiological treatment with

\footnotetext{
*Correspondence: mats.dehlin@vgregion.se

'Department of Rheumatology, University of Gothenburg, Gothenburg, Sweden

Full list of author information is available at the end of the article
}

ULT has been available since the 1950s [4] and previous studies from different countries have demonstrated suboptimal degree of treatment [5-8]. Furthermore, in recent years we have seen clinical guidelines with recommendations for ULT treatment earlier in the course of the disease [9], but there are few contemporary reports reflecting the current initiation and persistence with ULT and predictors thereof.

The aims of the present population-based cohort study were to determine: (1) the proportion of patients receiving ULT after gout diagnosis and predictors thereof, and (2) the proportion of patients persisting with ULT and predictors thereof. 


\section{Methods}

\section{Study design}

This is a population-based cohort study of patients with newly diagnosed gout, investigating the treatment with ULT and predictors thereof using regional health care registers linked with several national mandatory population-based registers.

Ethical approval was granted by the Regional Ethics Committee in Gothenborg, Sweden. Informed consent from the patients was waived since the study only involved register linkage.

\section{Setting}

Cases were identified from the health care register of all inhabitants in the Western Swedish Health Care Region (WSHCR), aged $\geq 18$ years, from 1 January 2011 through 31 December 2013. The area represents approximately $20 \%$ of the total population of Sweden and is considered to be representative for Sweden as a whole with regard to health status and demographics $[10,11]$. The Swedish health care system is tax-funded including private health care providers and all actors in this system report to the health registers.

\section{Data sources}

The Western Swedish Health Care Register (VEGA) was used to identify incident cases with gout and their comorbidities. This register contains information about all in- and outpatient health care contacts in both specialized and primary care clinics, by both private and public care providers. The register contains date of contact and diagnosis given by the treating physician according to the Swedish version of the International Statistical Classification of Diseases (ICD), (the tenth version of ICD (ICD-10) has been used in Sweden since 1997).

The Swedish Prescribed Drug Register [12] contains information about all prescribed drugs dispensed by Swedish pharmacies since July 2005. This register was used to determine dispensation of ULT. The Anatomical Therapeutic Chemical Classification System (ATC codes) was used to identify the medical treatments.

Demographic data were obtained from Statistics Sweden [10], which holds data on residency as well as data on socioeconomic factors (e.g. marital status and level of formal education) for all persons residing in Sweden.

All blood test results for creatinine from 1 January 2010 to 31 December 2013 were identified for all cases in four regional laboratory databases.

\section{Study population of gout}

An incident case of gout was defined as having been given a diagnosis of gout (ICD-10 M10, M14.0-14.1) at a visit in any care setting from 1 January 2011 to 31 December 2013 not preceded by a gout diagnosis or a dispensation of ULT during the preceding 5-year period, see Fig. 1 for more information.

\section{Exposures \\ Demographics}

Level of formal education was divided into three groups: 9 school years or less, 10 to 12 years and more than 12 years.

\section{Comorbidities}

Diabetes, common cardiovascular comorbidities (ischemic heart disease, arrhythmias, heart failure, peripheral vascular disease, cerebrovascular disease), renal disease and creatinine values were identified for all cases at the date of first gout diagnosis, date of first ULT dispensation and date of ULT stop. Comorbidities were defined as the presence of at least one prior visit to a physician in any care setting or hospitalization with a corresponding ICD-10-coded diagnosis (for ICD10 codes see Additional file 1: Table S1). A metabolic cardiovascular comorbidity index $(\mathrm{MCCI})$ was computed, where the following conditions each rendered one point giving a maximum of six points: ischemic heart disease, arrhythmias, heart failure, peripheral vascular disease, cerebrovascular disease and diabetes (for ICD10 codes and details see Additional file 2: Table S2). Estimated glomerular filtration rate (eGFR) was calculated according to the Chronic Kidney Disease Epidemiology Collaboration (CKD-EPI) [13] using the creatinine value closest to the date of first gout diagnosis within 1 year before until 1 month after that date. Furthermore, we made the assumption that none of the cases were of African-American origin, since these, according to

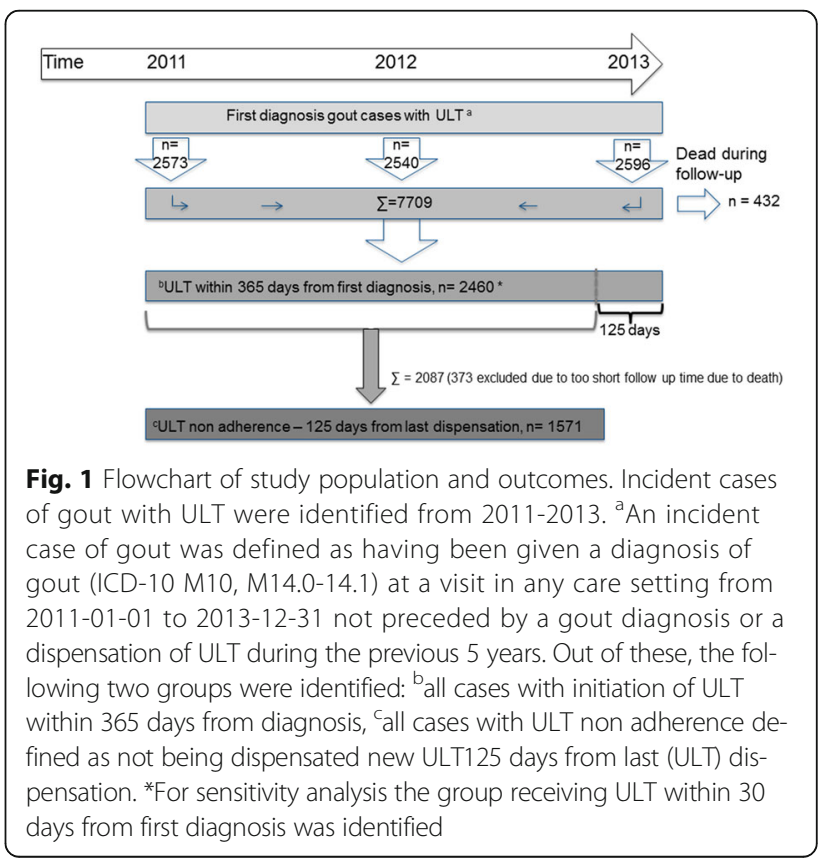


population statistics, represent less than $0.1 \%$ of the population. eGFR were divided into four ranges: "normal kidney function" defined as eGFR $>60 \mathrm{~mL} / \mathrm{min} /$ $1.73 \mathrm{~m}^{2}$, "reduced kidney function" $60-31 \mathrm{~mL} / \mathrm{min} /$ $1.73 \mathrm{~m}^{2}$, "severely reduced kidney function" $30-10 \mathrm{~mL} /$ $\mathrm{min} / 1.73 \mathrm{~m}^{2}$ and $<10 \mathrm{~mL} / \mathrm{min} / 1.73 \mathrm{~m}^{2}$ "end-stage kidney failure".

\section{Outcomes}

Among all the incident gout cases identified from 2011 to 2013 two binary outcomes were defined. First, all incident cases with initiation of ULT within 365 days from diagnosis. Second, of those starting ULT, whom had not persisted with therapy, defined as no dispensation $\geq 125$ days from the last dispensation. The choice of 125 days was based on the Swedish Pharmaceutical Benefit Scheme, which reimburse a maximum of 90 days drug supply at one purchase occasion [14]. In practice, packages for 100 days are often dispensed because of package sizes of 98 or 100 units. Thus, allowing for at least $80 \%$ adherence, one filled prescription would last for a maximum of 125 days. For sensitivity analysis, all incident cases with initiation of ULT within 30 days from diagnosis were identified. For further information, see Fig. 1.

Dispensation of ULT prescriptions included allopurinol (M04AA01), febuxostat (M04AA03), and probenecid (M04AB01).

\section{Statistical analysis}

Descriptive statistics were used to summarize the demographic characteristics. Predictors (sex, age, level of education, comorbidity, renal disease, kidney function and year of gout diagnosis) for initiation of ULT within 365 days from diagnosis were assessed with Cox regression analyses. The proportional hazard assumption was visually evaluated and found valid in all included analyses. In addition, a sensitivity analyses was performed with all incident cases with initiation of ULT within 30 days from diagnosis to evaluate if point estimates were similar as in the analyses with 365 days of followup. Hazard ratios (HRs) with 95\% confidence intervals (CIs) were calculated. Predictors for the likelihood of not adhering to ULT after 125 days were assessed with logistic regression models and presented as odds ratios (ORs) with 95\% confidence intervals (CIs). All statistical analyses were performed using SAS 9.4 (SAS Institute Inc., Cary, NC, USA).

\section{Results}

In total, 7709 incident cases of gout from 2011 to 2013 were identified and included. Of these, $68 \%$ were male, average age was 66 years and more than a third (35\%) had low level of education, $\leq 9$ years, see Table 1 for details. Less than half of the cases (47\%), had diabetes or
Table 1 Baseline variables at time of gout diagnosis, ULT start and for ULT stop

\begin{tabular}{|c|c|c|c|}
\hline & $\begin{array}{l}\text { At gout } \\
\text { diagnosis }\end{array}$ & $\begin{array}{l}\text { At ULT } \\
\text { start }\end{array}$ & $\begin{array}{l}{ }^{\mathrm{a} A t} \text { ULT } \\
\text { stop }\end{array}$ \\
\hline$n$ & 7709 & 2460 & 1571 \\
\hline Male sex, \% & 68.4 & 71.9 & 71.3 \\
\hline Age, mean & 66.5 & 68.2 & 68.2 \\
\hline Level of education': 9 years or less, $\%$ & 35.1 & 37.5 & 38.2 \\
\hline Level of education: 10-12 years, \% & 41.8 & 41.8 & 42.5 \\
\hline Level of education: more than 12 years, $\%$ & 19.2 & 17.2 & 16.4 \\
\hline \multicolumn{4}{|l|}{$\begin{array}{l}\text { Metabolic cardiovascular comorbidity } \\
\text { index }(\mathrm{MCCl})^{c}, \%\end{array}$} \\
\hline 0 & 53.1 & 42.5 & 43.4 \\
\hline $1-2$ & 34.9 & 41.0 & 39.5 \\
\hline $3-4$ & 11.4 & 15.6 & 16.0 \\
\hline $5-6$ & 0.6 & 0.9 & 1.2 \\
\hline$>6$ & 0.00 & 0.00 & 0.00 \\
\hline Renal disease ${ }^{d}, \%$ & 12.1 & 17.8 & 18.8 \\
\hline "Normal kidney function"e, \% & 62.9 & 50.4 & 53.2 \\
\hline "Reduced kidney function"f, \% & 31.1 & 41.9 & 38.6 \\
\hline "Severely reduced kidney function"9, \% & 5.7 & 7.5 & 7.8 \\
\hline "End-stage kidney failure"th, \% & 0.3 & 0.2 & 0.4 \\
\hline $2011, \%$ & 33.4 & 26.1 & 13.3 \\
\hline $2012, \%$ & 33.0 & 35.8 & 36.4 \\
\hline $2013, \%$ & 33.7 & 38.1 & 50.4 \\
\hline
\end{tabular}

ULT urate-lowering treatment

a Defined as no ULT dispensation $\geq 125$ days since last dispensation

${ }^{\mathrm{b}}$ Missing data for level of education: $3.8 \%$ at gout diagnosis, $3.5 \%$ at ULT start and $2.9 \%$ at ULT stop

${ }^{\mathrm{C}}$ For definition (ICD-10 codes) of metabolic cardiovascular comorbidity index see Additional file 2: Table S2

${ }^{d}$ For definition (ICD-10 codes) of renal disease see Additional file 1: Table S1

e Defined as eGFR $>60 \mathrm{~mL} / \mathrm{min} / 1.73 \mathrm{~m} 2$

fDefined as eGFR $60-31 \mathrm{~mL} / \mathrm{min} / 1.73 \mathrm{~m} 2$

${ }^{9}$ Defined as eGFR $30-10 \mathrm{~mL} / \mathrm{min} / 1.73 \mathrm{~m} 2$

${ }^{\mathrm{h}}$ Defined as eGFR $<10 \mathrm{~mL} / \mathrm{min} / 1.73 \mathrm{~m} 2$

${ }^{\mathrm{e}-h}$ Creatinine value closest to date of first gout diagnosis within 1 year before until 1 month after, a third (2555) of the incident cases did not have a

creatinine value within 1 year before and 1 month after. The vast majority of these, 95\%, did not have renal disease. For more details, see Additional file 3: Table S3.

cardiovascular comorbidities and a diagnosed renal disease was present in $12 \%$ although decrease in kidney function defined as eGFR $<60 \mathrm{~mL} / \mathrm{min} / 1.73 \mathrm{~m}^{2}$ was present in as many as $37 \%$ (Table 1 ) and Additional file 3 : Table S3.

\section{The proportion of patients receiving ULT after gout diagnosis and predictors thereof}

Of the 7709 incident cases, 1444 (19\%) and 2460 (32\%) received ULT from the date of first gout diagnosis up through 30 and 365 days post-diagnosis respectively, see Fig. 2 . The vast majority was prescribed allopurinol, less 


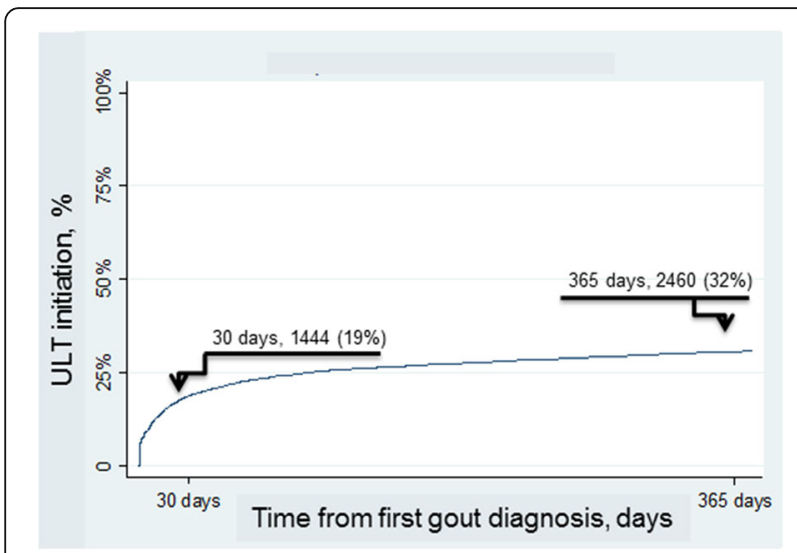

Fig. 2 Proportion of patients receiving ULT within 30 and 365 days from diagnosis respectively, in incident patients with gout than $2 \%$ received probenecid and febuxostat was not used at all.

Male sex, age $\geq 60$, "reduced kidney function" but not "end-stage kidney failure" by eGFR, presence of diagnosed renal disease and presence of $\geq 1$ comorbidity all significantly $(p<0.05)$ predicted receiving ULT within 365 days by univariate COX regression (Table 2). Two different multivariate analyses were performed, one with renal disease defined by ICD10 coding and the other with renal function by eGFR as a proxy for renal pathology. Male sex and presence of $\geq 1$ comorbidities both significantly $(p<0.05)$ and positively predicted start of ULT within 365 days in both models (Table 2). Renal disease also predicted start of ULT. When using eGFR as a proxy for renal pathology "reduced kidney function" but not "end-stage kidney failure" predicted start of

Table 2 Predictors for first ULT dispensation within 365 days after diagnosis

\begin{tabular}{|c|c|c|c|c|}
\hline & \multirow[b]{2}{*}{$\begin{array}{l}\% \text { with } \\
\text { event }\end{array}$} & \multicolumn{3}{|c|}{ Predictors for ULT dispensation within 365 days (COX) } \\
\hline & & $\begin{array}{l}\text { Univariate hazard ratio } \\
95 \% \mathrm{Cl}\end{array}$ & $\begin{array}{l}\text { Multivariate* hazard ratio } \\
95 \% \mathrm{Cl} \text { (with eGFR) }\end{array}$ & $\begin{array}{l}\text { Multivariate }{ }^{* *} \text { hazard ratio } \\
95 \% \mathrm{Cl} \text { (with renal disease) }\end{array}$ \\
\hline Male (ref) & 30.33 & & & \\
\hline Female & 26.39 & $0.87(0.79-0.95)$ & $0.87(0.79-0.97)$ & $0.86(0.78-0.94)$ \\
\hline \multicolumn{5}{|l|}{ Age, years } \\
\hline 20-49 (ref) & 22.84 & & & \\
\hline $50-59$ & 23.21 & $1.03(0.87-1.22)$ & $0.90(0.72-1.12)$ & $0.96(0.81-1.14)$ \\
\hline $60-69$ & 30.14 & $1.38(1.19-1.59)$ & $0.90(0.74-1.10)$ & $1.15(0.99-1.34)$ \\
\hline $70-79$ & 34.19 & $1.61(1.40-1.86)$ & $0.82(0.67-1.00)$ & $1.25(1.07-1.46)$ \\
\hline $80-$ & 30.74 & $1.46(1.26-1.69)$ & $0.57(0.46-0.71)$ & $1.03(0.87-1.21)$ \\
\hline \multicolumn{5}{|l|}{ Level of education } \\
\hline$\leq 9$ years (ref) & 31.10 & & & \\
\hline 10-12 years & 28.78 & $0.92(0.83-1.31)$ & & \\
\hline$>12$ years & 26.32 & $0.83(0.73-0.93)$ & & \\
\hline \multicolumn{5}{|l|}{$\mathrm{MCCl}$} \\
\hline 0 (ref) & 23.53 & & & \\
\hline $1-2$ & 34.20 & $1.57(1.44-1.72)$ & $1.29(1.15-1.45)$ & $1.45(1.31-1.60)$ \\
\hline$>2$ & 38.79 & $1.91(1.69-2.15)$ & $1.43(1.23-1.66)$ & $1.73(1.51-1.99)$ \\
\hline \multicolumn{5}{|l|}{ Renal disease } \\
\hline 0 (ref) & 27.48 & & & \\
\hline 1 & 40.75 & $1.67(1.50-1.87)$ & & $1.47(1.31-1.64)$ \\
\hline eGFR >60 mL/min/1.73 m² "normal kidney function” (ref) & 26.56 & & & \\
\hline eGFR 60-31 mL/min/1.73 m² "reduced kidney function" & 44.33 & $1.91(1.73-2.11)$ & $2.11(1.88-2.37)$ & \\
\hline $\begin{array}{l}\text { eGFR } 30-10 \mathrm{~mL} / \mathrm{min} / 1.73 \mathrm{~m}^{2} \text { "severely reduced kidney } \\
\text { function" }\end{array}$ & 44.71 & $2.01(1.67-2.41)$ & $2.31(1.90-2.82)$ & \\
\hline eGFR <10 mL/min/1.73 m² "end-stage kidney failure" & 30.77 & $1.14(0.43-3.04)$ & $1.17(0.44-3.12)$ & \\
\hline \multicolumn{5}{|l|}{ 2011, ref } \\
\hline 2012 & & $1.10(0.99-1.21)$ & & \\
\hline 2013 & & $1.02(0.92-1.13)$ & & \\
\hline
\end{tabular}

ULT urate-lowering treatment, $\mathrm{Cl}$ confidence interval, eGFR estimated glomerular filtration rate, $M C C I$ metabolic cardiovascular comorbidity index *Adjusted for sex, age, comorbidities and eGFR

${ }^{* *}$ Adjusted for sex, age, comorbidities and renal disease defined by ICD 10 coding 
ULT (Table 2). Age 70-79 positively predicted start of ULT when renal disease was defined by ICD10 coding (Table 2). The effects of level of education disappeared when adjusting for age and were therefore not included in the multivariate analyses. There was no significant effect of year of gout diagnosis, which suggests no major changes in treatment patterns during the study period.

A sensitivity analysis evaluating predictors for initiation of ULT up through 30 days after diagnosis of gout showed similar point estimates (Additional file 4: Table S4).

\section{The proportion of patients not persisting with ULT and predictors thereof}

Of the 7709 incident cases, 2087 (27\%) were followed up after their first ULT dispensation, a start of therapy which did not necessarily have to be within 365 days after diagnosis. Of these, 1571 (75\%) did not persist with ULT treatment. The risk for not persisting with ULT was significantly $(p<0.05)$ higher for those with age $<50$ years, total lack of comorbidities, no renal disease and "normal kidney function" by eGFR (Table 3), with similar point estimates in models using alternatively ICD coding or eGFR as a proxy for renal pathology.

There was no significant effect of year for gout diagnosis, which suggests no major change in treatment patterns during the study period.

\section{Discussion}

We identified 7709 incident cases of gout in the WSHCR, aged $\geq 18$ years from 1 January 2011 through 31 December 2013. Of these, only 32\% received ULT within 365 days after first gout diagnosis. Positive predictors thereof were presence of diabetes or cardiovascular comorbidity, renal disease, and "reduced kidney function" but not "end-stage kidney failure". A positive predictive effect of age was only seen in one group, 70-79 years, and only in the multivariate model adjusted for renal disease. The vast majority did

Table 3 Predictors for not adhering to ULT

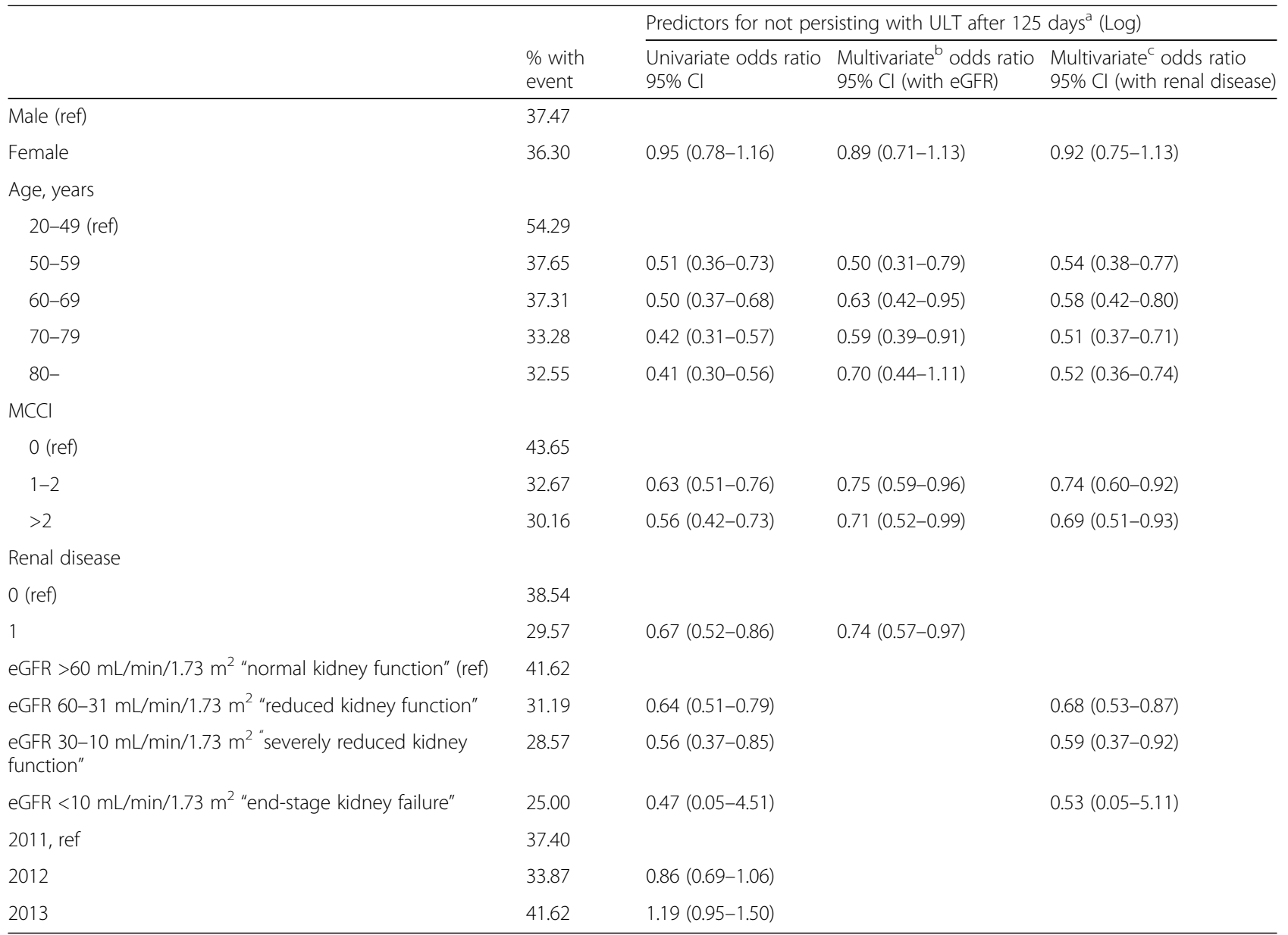

ULT urate-lowering treatment, $\mathrm{Cl}$ confidence interval, eGFR estimated glomerular filtration rate, $\mathrm{MCCl}$ metabolic cardiovascular comorbidity index ${ }^{a}$ Defined as no ULT dispensation 125 days after last dispensation

${ }^{\mathrm{b}}$ Adjusted for sex, age, comorbidities, and eGFR

${ }^{c}$ Adjusted for sex, age, comorbidities and renal disease 
not persist with ULT and risks for not persisting with ULT were higher for those with age $<50$ years, total lack of comorbidities, no renal disease and "normal kidney function" by eGFR.

There are several possible limitations to our study. First, our case definitions were based on diagnoses of gout made in the clinical situation rather than according to the different proposed classification criteria [15-20], which may have led to misclassification bias. Previous studies by us in this setting have demonstrated a high validity for a more strict definition of gout requiring two or more visits with a gout diagnosis in primary care [21]. However, the comorbidity pattern is similar between the more strict definition and the one used in the present study [22] suggesting similar validity for the two definitions. Second, gout has an intermittent course with possibly long clinically silent phases, which may hamper any attempt to identify true incident cases of the disease. Third, there may be more factors such as other medications and comorbidities not covered in our analysis which may affect the initiation of ULT. Fourth, we had no specific data to elucidate to what extent non-persistance was explained by factors such as perceived lack of efficacy, side effects experienced, or simply patient or practitioner preference.

There are also several strengths of the present study. First, using the mandatory national health registers in Sweden, with a virtually complete coverage on an individual level, makes the results population representative. Second, loss to follow-up is not a problem since the Swedish population is possible to follow to death through the central statistics in Sweden. Third, the estimates for ULT treatment, laboratory data and socioeconomic data were retrieved from independent data sources.

Predictors for initiation of ULT in gout is not a wellstudied topic, maybe reflecting some uncertainty of when to start treatment. Kuo et al. [23] showed in a study about eligibility for ULT in incident gout that the cumulative probability of fulfilling any treatment indication for ULT was $44 \%$ at diagnosis and $61 \%$ after 1 year. They also reported findings similar to ours with sex, comorbidity and kidney disease being predictors for initiation of ULT. Furthermore, persistence in our study was negatively affected by age $<50$ years, which is in accordance to a historical study (by Horsburgh et al. [24]) on allopurinol prescription and persistence in New Zealand 2005/06.

Predictors of persistence with ULT was also investigated by Harrold et al. [25] in 4166 patients with gout in the US from 2000 to 2006, reporting age $<50$ and fewer comorbidities to predict worse persistence, results that are similar to our findings with lack of comorbidities significantly predicting low persistence. "Normal renal function" (eGFR $>60)$ or "end-stage renal failure" $(<10 \mathrm{~mL} / \mathrm{min} /$ $1.73 \mathrm{~m}^{2)}$ respectively predicted worse persistence with
ULT in the present study. Interestingly, Sarawate et al. [26], in a managed care database study from 2000 to 2002 in the US also found that presence of renal impairment negatively affected persistence with ULT. However, the renal impairment in their study was based on diagnosis rather than eGFR hampering exact comparison. Finally, Briesacher et al. [27] showed in a study from 2008 that gout had by far the poorest persistence with therapy when compared to six other chronic diseases, where only $37 \%$ of patients with gout achieved at least $80 \%$ persistence with ULT. This study also showed that increasing age and presence of comorbidities improved persistence for all studied diseases, including gout. Compared to all these studies, our results are based on more contemporary data and suggest that low levels of initiation and persistence of ULT continues to be a health care problem. Furthermore, we could not demonstrate any change in treatment pattern during our study period.

Some of the negative prognostic markers favoring ULT initiation, highlighted in the proposed EULAR guidelines from 2016 [9], have already been acted upon by the clinicians in our study, such as the presence of comorbidities and renal impairment while others, such as age below 40, on the contrary did not predict ULT initiation. There are still considerable gaps of knowledge when initiation of ULT is appropriate after first diagnosis of gout. On the other hand, our results clearly show that the proportion of patients receiving ULT in diagnosed gout continuous to be low. In the present study, we have focused on patient characteristics affecting ULT, which of course is not the only explanation. Different aspects of clinical inertia come to play here. The physicians knowledge and attitude to guidelines is a problem well observed and might be improved by shared decision making and enhanced guideline development and dissemination [28]. Furthermore, consultation patterns with patients not consulting for repeated attacks when having acute anti-inflammatory treatment at hand thus not giving the physician the opportunity to discuss ULT, awareness of patient attitudes, knowledge and preferences towards gout and ULT are important factors to consider in the strive for improvement $[29,30]$.

\section{Conclusions}

In the present study, we demonstrate that initiation and persistence to ULT continues to be poor, although predictors thereof indicate better results for those with a stronger indication for therapy. The long-term consequences of poor ULT treatment of gout need to be exactly determined. Nevertheless, future research should also aim at identifying and addressing the barriers to 
starting and persisting with ULT over time and to overcome these.

\section{Additional files}

Additional file 1: Table S1. Definition of comorbidities by ICD10 codes and ULT by ATC codes. (DOCX $91 \mathrm{~kb}$ )

Additional file 2: Table S2. Metabolic cardiovascular comorbidity index (MCCl). (DOCX $91 \mathrm{~kb}$ )

Additional file 3: Table S3. Distribution of kidney function defined by eGFR and presence of renal disease in incident cases at date of first gout diagnosis and missing. (DOCX $92 \mathrm{~kb}$ )

Additional file 4: Table S4. Predictors for first ULT dispensation within 30 days after diagnosis. (DOCX $93 \mathrm{~kb}$ )

\section{Abbreviations}

ATC: anatomical therapeutic chemical classification system; Cls: confidence intervals; CKD-EPI: Chronic Kidney Disease Epidemiology Collaboration; CVD: cardiovascular disease; eGFR: estimated glomerular filtration rate; HRs: hazard ratios; ICD: International Statistical Classification of Diseases; MCCl: metabolic cardiovascular comorbidity index; ORs: odds ratios; ULT: urate-lowering therapy; VEGA: Western Swedish Health Care Register; WSHCR: Western Swedish Health Care Region

\section{Acknowledgements}

Not applicable.

\section{Funding}

AstraZeneca was the funding source for this study, and a member of the study steering committee that carried overall responsibility for the study concept and design. Project management was provided by Gothia Forum. The statistical analysis plan was agreed on by the study steering committee, and data analysis was performed by Gothia Forum. AstraZeneca took part, as member of the study steering committee, in the interpretation of the data and the drafting of the manuscript. All researchers assigned as authors state their complete independence from the funders, with regard to this study.

\section{Availability of supporting data}

The dataset is still subject to further analyses, but will continue to be held and managed by Salgrenska University Hospital, Gothenburg, Sweden. Relevant anonymized patient-level data are available on reasonable request from the authors.

\section{Authors' contributions}

MD was responsible for the manuscript draft and finalization and participated in the study planning. EE was responsible for statistical analyses and participated in the study planning. MP, UE and GT participated in the study conception, design and statistical analysis and helped in drafting the manuscript. $L J$ participated in the study conception and the statistical analyses and was responsible for handling of data and the study database and helped to draft the manuscript. All authors read and approved the final manuscript.

\section{Authors' information}

Not applicable.

\section{Competing interests}

The authors declare that they have no competing interests.

\section{Consent for publication}

Not applicable.

\section{Ethics approval and consent to participate}

Ethical approval for the study was granted from the Ethical Review Board of Gothenburg, Sweden. Patient consent was waived, as data were derived from administrative registers that do not require such.

\section{Author details}

'Department of Rheumatology, University of Gothenburg, Gothenburg, Sweden. ${ }^{2}$ Gothia Forum, Gothenburg, Sweden. ${ }^{3}$ Swedish National Data Service, University of Gothenburg, Gothenburg, Sweden. ${ }^{4}$ Health Metrics, University of Gothenburg, Gothenburg, Sweden. ${ }^{5}$ AstraZeneca Nordic-Baltic, Södertälje, Sweden.

Received: 20 September 2016 Accepted: 15 December 2016

Published online: 17 January 2017

\section{References}

1. Richette P, Perez-Ruiz F, Doherty M, Jansen TL, Nuki G, Pascual E, Punzi L, So AK, Bardin T. Improving cardiovascular and renal outcomes in gout: what should we target? Nat Rev Rheumatol. 2014;10(11):654-61.

2. Grimaldi-Bensouda L, Alperovitch A, Aubrun E, Danchin N, Rossignol M, Abenhaim L, Richette P, Group PGM. Impact of allopurinol on risk of myocardial infarction. Ann Rheum Dis. 2015;74(5):836-42.

3. Chen JH, Lan JL, Cheng CF, Liang WM, Lin HY, Tsay GJ, Yeh WT, Pan WH. Effect of urate-lowering therapy on the risk of cardiovascular disease and all-cause mortality in patients with gout: a case-matched cohort study. J Rheumatol. 2015;42(9):1694-701.

4. Boger WP, Strickland SC. Probenecid (benemid); its uses and side-effects in 2,502 patients. AMA Arch Intern Med. 1955;95(1):83-92.

5. Kuo CF, Grainge MJ, Mallen C, Zhang W, Doherty M. Rising burden of gout in the UK but continuing suboptimal management: a nationwide population study. Ann Rheum Dis. 2015;74(4):661-7.

6. Kuo CF, Grainge MJ, See LC, Yu KH, Luo SF, Zhang W, Doherty M. Epidemiology and management of gout in Taiwan: a nationwide population study. Arthritis Res Ther. 2015;17:13.

7. Mikuls TR, Farrar JT, Bilker WB, Fernandes S, Schumacher Jr HR, Saag KG. Gout epidemiology: results from the UK General Practice Research Database, 1990-1999. Ann Rheum Dis. 2005;64(2):267-72.

8. Dehlin M. Incidence and prevalence of gout in western Sweden. Arthritis Res Ther. 2016;18:1062-6.

9. Richette P, Doherty M, Pascual E, Barskova V, Becce F, Castaneda-Sanabria J, Coyfish M, Guillo S, Jansen TL, Janssens H, et al. 2016 updated EULAR evidence-based recommendations for the management of gout. Ann Rheum Dis. 2017;76(1):29-42.

10. Statistiska C: Folkmängden efter region, civilstånd, ålder och kön. År 1968-2014 http://www.scb.se. 2012.

11. Ministry of Health and Social Affairs SGO: Updated high-cost protection outpatient care and medication. Health and Social Affairs; 2011. https:// www.socialstyrelsen.se/Lists/Artikelkatalog/Attachments/19238/2013-12-1. pdf. Accessed 31 Dec 2012.

12. Socialstyrelsen: Läkemedelsregistret http://www.socialstyrelsen.se/register/ halsodataregister/lakemedelsregistret. Accessed 31 Dec 2012.

13. Levey AS, Stevens LA, Schmid CH, Zhang YL, Castro 3rd AF, Feldman HI, Kusek JW, Eggers $P$, Van Lente F, Greene T, et al. A new equation to estimate glomerular filtration rate. Ann Intern Med. 2009;150(9):604-12.

14. Act (2002:687) on Pharmaceutical Benefits e: (4 July 2002, 2002). Pharmaceutical Benefits; 2002. http://www.tlv.se/Upload/English/ENGordinance-2002-687.pdf. Accessed 31 Dec 2012.

15. Kellgren JH, Jeffrey MR, Ball J. The epidemiology of chronic rheumatism. 1 vol. Oxford: Blackwell Scientific; 1963. p. 295-7.

16. Decker J. Report from the subcommittee on diagnostic criteria for gout. In: Bennett PH, Wood PHN, eds. Population studies of the rheumatic diseases. Proceedings of the Third International Symposium, New York, June 5-10, 1966. Amsterdam: Excerpta Medica Foundation. 1968;1968:385-7.

17. Wallace SL, Robinson H, Masi AT, Decker JL, McCarty DJ, Yu TF. Preliminary criteria for the classification of the acute arthritis of primary gout. Arthritis Rheum. 1977;20(3):895-900.

18. Pelaez-Ballestas I, Hernandez Cuevas C, Burgos-Vargas R, Hernandez Roque L, Teran L, Espinoza J, Esquivel-Valerio JA, Goycochea-Robles MV, Aceves FJ, Bernard AG, et al. Diagnosis of chronic gout: evaluating the American College of Rheumatology proposal, European League Against Rheumatism recommendations, and clinical judgment. J Rheumatol. 2010;37(8):1743-8.

19. Janssens HJ, Fransen J, van de Lisdonk EH, van Riel PL, van Weel C, Janssen M. A diagnostic rule for acute gouty arthritis in primary care without joint fluid analysis. Arch Intern Med. 2010;170(13):1120-6.

20. Neogi $T$, Jansen $T L$, Dalbeth N, Fransen J, Schumacher HR, Berendsen $D$, Brown M, Choi H, Edwards NL, Janssens HJ, et al. 2015 Gout classification 
criteria: an American College of Rheumatology/European League Against Rheumatism collaborative initiative. Ann Rheum Dis. 2015;74(10):1789-98.

21. Dehlin M, Stasinopoulou K, Jacobsson L. Validity of gout diagnosis in Swedish primary and secondary care - a validation study. BMC Musculoskelet Disord. 2015;16(1):149.

22. Drivelegka P, Jacobsson L, Sigurdardottir V, Svärd A, Dehlin M. Comorbidity pattern at the time of gout diagnosis: a population- and register-based case-control study from Western Sweden. Ann Rheum Dis. 2016;75(Suppl 2): 381. doi:10.1136/annrheumdis-2016-eular.4934.

23. Kuo CF, Grainge MJ, Mallen C, Zhang W, Doherty M. Eligibility for and prescription of urate-lowering treatment in patients with incident gout in England. JAMA. 2014;312(24):2684-6.

24. Horsburgh S, Norris P, Becket G, Arroll B, Crampton P, Cumming J, Keown S, Herbison P. Allopurinol use in a New Zealand population: prevalence and adherence. Rheumatol Int. 2014;34(7):963-70.

25. Harrold LR, Andrade SE, Briesacher BA, Raebel MA, Fouayzi H, Yood RA, Ockene IS. Adherence with urate-lowering therapies for the treatment of gout. Arthritis Res Ther. 2009;11(2):R46.

26. Sarawate CA, Brewer KK, Yang W, Patel PA, Schumacher HR, Saag KG, Bakst AW. Gout medication treatment patterns and adherence to standards of care from a managed care perspective. Mayo Clin Proc. 2006;81(7):925-34.

27. Briesacher BA, Andrade SE, Fouayzi H, Chan KA. Comparison of drug adherence rates among patients with seven different medical conditions. Pharmacotherapy. 2008;28(4):437-43.

28. Lavoie KL, Rash JA, Campbell TS. Changing provider behavior in the context of chronic disease management: focus on clinical inertia. Annu Rev Pharmacol Toxicol. 2016.

29. Reach G. Treatment adherence in patients with gout. Joint Bone Spine. 2011;78(5):456-9

30. Spencer K, Carr A, Doherty M. Patient and provider barriers to effective management of gout in general practice: a qualitative study. Ann Rheum Dis. 2012;71(9):1490-5.

\section{Submit your next manuscript to BioMed Central and we will help you at every step:}

- We accept pre-submission inquiries

- Our selector tool helps you to find the most relevant journal

- We provide round the clock customer support

- Convenient online submission

- Thorough peer review

- Inclusion in PubMed and all major indexing services

- Maximum visibility for your research

Submit your manuscript at www.biomedcentral.com/submit

) Biomed Central 